\title{
Exploration of Schema in Business English Translation
}

\author{
Xiangyue $\mathrm{Yu}$ \\ Department of English, School of Foreign Languages \\ Huzhou Teachers College, Huzhou 313000, Zhejiang, China \\ Tel: 86-572-237-5598 E-mail: flsxyy@163.com
}

Received: May 9, 2011

Accepted: September 17, 2011

Published: December 1, 2011

doi:10.5539/ells.v1n2p141

URL: http://dx.doi.org/10.5539/ells.v1n2p141

[Fund project]The stage achievement of the 2010 planning fund project for the research of humanities and social sciences financed by the Ministry of Education of the People's Republic of China (Project Approval Number: 10 YJA740119)

\begin{abstract}
Translators as the first readers serve as a bridge between the source language and target language. Translation is an important ability of language application and an important way for people to acquire information. Nowadays, since the business communication among countries becomes more and more frequent, to get business information also becomes increasingly important. Schema theory is a theory that cognitive psychologists use to explain the psychological process of understanding. According to the schema theory, to make full use of schemata - background knowledge that one has can promote the understanding, which can be applied to Business English translation. As to the features of Business English translation, the activation, construction, and extension of the appropriate schemata can enhance the translators' translation ability.
\end{abstract}

Keywords: Schema theory, Activation of schemata, Construction and extension of schemata, Business English translation

\section{Introduction}

Translation is an important approach to get information, and to get information quickly and correctly is very important for businessmen. In the era of knowledge-based economy, acquiring information efficiently and correctly is very important for businessmen to look for business opportunities and do business abroad. Thus, based on a good understanding of Business English texts, it is of vital importance for the translators to boost the translation ability. Schema theory is basically a theory about knowledge. It is about how knowledge is used in particular ways. This theory contributes to the translation ability. As to the characteristics of Business English translation, schema theory can be used in comprehension process of Business English texts to solve the problems in business translation. The activation, construction and application of schemata can help translators deeply understand the texts and conduct a better translation.

\section{Understanding and Interpretation of Schema}

The notion of schema is firstly proposed by Kant, German philosopher. In his book, he explained the philosophical meaning of schema: schemata are pure concepts that exist in human's mind. (Kant, 2003) That is the connections between concepts and perception objects. He thought when a person received new information, new concepts, new ideas, he could have a sense only when these new things were connected with his inherent knowledge in his mind. (Zhao Yanfang, 2000) After that, modern psychologist Bartlett (1932) defined schema as "an active organization of past reactions, or past experience." (David Carroll, 2000) He did some experiment, attempting to show that remembering is a process in which we retain the overall gist of an event and then reconstruct the details from this overall impression and examine the guiding function of schemata in the reconstruction process. (Gui Shichun, 2000) In the late 1970s, American artificial intelligent expert D.E. Rumelhart had done a lot of research and the concept of schema had been developed into a complete theory. According to this theory, any text itself didn't have any language meaning, it only guides readers or listeners to restore meanings on the basis of their existing knowledge. Schema is the knowledge unit that exists in people's mind. (David Carroll, 2000) Firstly, translation needs inputting certain information via reading, then translators search the schemata that can explain this information in the memory, hence the texts can be well understood when the schemata are enough to explain the information. 
More recently, Anderson and Wilson gave schema a more specific and widely accepted definition: a schema is an abstract structure of knowledge. (Zuo Li, 2007) It is structured in the sense that it indicates relations between constituent concepts. It is abstract in the sense that one schema has the potential to cover a number of texts that differ in particulars. Therefore, schema theory explains how people's existing knowledge affects the comprehension process.

Cook defines schema as "a mental representation of a typical instance". He emphasizes the cognitive characteristics of schema. This allows us to connect the forthcoming information with the known information. So it covers the knowledge of the world, ranging from everyday knowledge to specialized knowledge. In other words, schema can play an important role in translation.

Schema can be seen as the organized background knowledge. The act of schema has two basic fountainheads. (Zhang Biyin,1995) They're conceptual drive and data drive. Conceptual drive is that a schema can activate the sub-schema, while data drive is that the sub-schema brings in the schema. That is, conceptual drive is from the whole to parts and data drive is opposite. These two kinds of drives make the schema work and facilitate comprehension. Therefore, the schema theory is an important and useful theory in comprehension.

\section{Schema in Business English Translation}

Schema theory plays an important role in translation. Business English is different from General English. It has its own features both in lexis and syntactic structures. Towards these features, schema theory will find a way out resolving the problems occurring in Business English translation.

\subsection{Features of Business English translation}

Translators as the first readers serve as a bridge between the source language and target language. So translation is a psycholinguistic process. Readers start with a set of linguistic symbols that have been chosen by writers to express the thoughts that they wish to express. (Wedell, 1995) Business English translation is formed on the basis of General English translation, so they have lots of relations. But Business English is a kind of English for specific purpose, and it is more professional. Therefore, Business English translation has obvious features that differ from those of General English.

\subsubsection{Features of lexis}

Business covers a wide scope, such as commerce, marketing, management, tourism, logistics, International Business Law etc. So Business English is rich in vocabulary. (Yang Chaoguang, 2007) Business English is applied to business field. The most obvious characteristic is the professionalism of lexis. The lexis has a relatively narrow meaning, and is more technical and professional. Many words used in General English are used in Business English, but the meanings are totally different. And some words still have certain connections between the basic meaning and the meaning in business context, while others have no relations at all. (Wang Junjie, Wu Fang, 2008) For example, the basic meaning of "trust" is the belief that somebody or something is good, sincere, honest, etc. and will not try to harm or deceive you, but the meaning in Business English is a group of companies that work together legally to reduce competition, control price, etc. "Trust" in business is a faithful relationship among companies, somewhat like a faithful friendship.

There are still some connections in different contexts. So it is with the word "promotion". Its basic meaning is a move to a more important job or rank in a company or an organization, while the meaning in Business English is activities done in order to increase the sales of a product or service; a set of advertisement for particular product or service.

But the following words totally have no connections between Business English and General English. "Average" means the result of adding several amounts together, finding a total, and the total by the number of amounts, while the meaning in Business English is marine loss. The basic meaning of "commission" is an official group of people who have been given responsibility to control something, or to find out about something, usually for the government, while another meaning is an amount of money that is paid to somebody for selling goods and which increases with the amount of goods are sold. There are lots of such words. In addition, because of the need of time-saving principle and the frequency of business trade, there are a large number of abbreviated terms. Advertisement is clipped to Ads, bill of landing, $\mathrm{B} / \mathrm{L}$. And CIF means cost, insurance and freight. These abbreviations are acquainted by the businessmen.

With the development of international business trade and high technology, more and more new words are created and being accepted by businessmen, like knowledge-based economy, E-business, soft-landing. What's more, there are many words involving WTO and trade, like import quota, protective tariff and certificate of origin. 
In Business English translation, there are many long sentences with quite complicated syntactic structures, and sometimes one sentence is as long as a paragraph. For example, Yet despite substantial evidence that current trade policies have resulted in massive trade deficits and job losses, the Bush Administration is pressing Congress for "fast track" trade negotiating authority, by which the President could submit trade agreements to Congress for a yes or no vote without amendment. (Wang Guanfu, 2002) It is a compound-complex sentence, containing forty-seven words and different clauses. In Business English translation, many sentences are of this kind. So it adds the difficulties for the translators to understand the content.

\subsubsection{Features of structure}

Different from various kinds of formats of General English texts, the format of Business English texts is quite fixed. The genres of Business English texts are basically the same. The logic of structures is reasonable, and meaning is coherent. The logical legitimacy includes reasonable sentence structure, reasonable paragraphs and reasonable text thoughts. The meaning coherence is the meaning coherence between sentences, the content coherence between paragraphs and the thought coherence in content. The structure of Business English texts has such characteristics as complete structure, close logic. So, when translating this kind of texts, translators couldn't confine themselves in paragraphs, sentences or some words, and they should pay attention to the gross structure and logical thought, otherwise they will fail to understand what the writer means completely and thoroughly, or even they will distort the real intention of writing. That the translators grasp the whole structure and thinking logic can help them find the needed information rapidly and increase the efficiency of translation.

\subsection{Function of schema in Business English translation}

As to the features of Business English translation, schema theory can find out a way to solve the problems in translation process, for there are many useful functions of schema used in Business English translation. Generally speaking, there are three main functions.

\subsubsection{Function of dealing with information}

Schema is the previous knowledge existing in the mind. The previous knowledge can turn translators' attention to the familiar information in the translation process. The process of comprehension is the process of interaction between schema existing in the mind and the information in the text. When translators connect the previous schema and the information provided by the texts, they will get the meaning. The first step of translation is to input certain information, and then search the schema relative to this information. When the related schema is found, the former schema will be used to compare with the new information and then translators analyze and work on it. Thus the new information will be understood. So it is a process of dealing with information.

When translators receive the new information, the input of the new information will activate some related points in schema. Then according to the need of translation, translators will automatically reorganize and restructure the activated schema, then gain the concrete meaning of new information. So translation is a complex process of gaining information, processing information and creating information through the media of the texts.

If translators don't have corresponding schema with the texts, they cannot understand the texts. When translators have the corresponding schema, nevertheless the information given by the author is not enough to activate the schema; they cannot understand the texts either. So it is an interaction between schema and information. When translators have the basic business knowledge in translating the Business English texts, this knowledge becomes schema stored in memory. Once translators receive the new information, they will connect it with the knowledge stored in the mind - schema. Then schema will handle the next step information.

\subsubsection{Function of improving memory}

Brain works in a complicated way. In face of an order, the brain has two sets of neuron going to work quickly. One is accepting and dealing with the information, and the other is the storage area of the relative knowledge to finish the order.(Yuan Bo, 1997) That is to say, the process of comprehension is actually the process of intercoordination of language knowledge and schema knowledge. As we know, the above discussion has already testified that schema has important relation with the handling of the information. When translators work on the information, their attention will be attracted on the important information under the affect of schema. This attention on important information also helps the brain remember it more clearly. When translators deal with the information, they will pick out the important one, so the brain will naturally pay more attention to it and remember it more impressively. And this information will be added to the former and corresponding schemata. So it strengthens the schemata. These schemata are connected each other, making the brain remember more relative information. In this way, schema can improve the memory. 


\subsubsection{Improvement of comprehension}

Comprehension not only depends on the information the texts convey and the nature of it, but also bases upon translators' background knowledge, such as education situation, cultural background, life experience, aesthetic interest and so on.

If one who has little knowledge about business reads Business English texts, s/he cannot understand the content even though s/he looks up all the words related with business in a dictionary and analyses the grammar clearly. (Lin Ting, 1996) On the contrary, one who has professional knowledge of business can deduce the meaning of the texts and has a right understanding of the content, even though there are some trouble of words and grammar, which indicates the schema is functioning. In a sense, schema can be seen as the background knowledge. Before translating, translators ought to widely browse some correspondent background knowledge of Business English texts. According to the language information in the texts, they can analyze and guess the meaning with the help of background knowledge. Therefore, the schema has played an active role in the whole translation process.

\section{Application and Construction of Schema in Business English Translation}

Anderson mentioned two types of situation involving schemata. One is the activation of existing schemata while the other involves the construction of new schemata. These two activities are very essential for translators. The application of schema theory can be divided into two parts: the activation and the construction of schema. (Zuo Li, 2007)

\subsection{Activation of schemata}

As the usefulness of the schema in Business English translation, it is necessary to activate the schema. There are mainly three aspects as follows:

\subsubsection{Activation of background knowledge}

Business English translation involves many areas connected with economy. There are analytic texts on economy events in a certain country or areas at a certain time and also the attention of the development of global economy (Wu Feng, 2005). The analytic texts were closely connected with the local economy at that time with styles of wide range, professionalism and effectiveness. Therefore, it is necessary for translators to know the local politics, economy and culture and have certain professional knowledge like economics, management, trading and so on. It is a key point to possess the professional background knowledge when translating Business English texts. Translators can completely understand the content of the texts only when they have basic background knowledge. For example, "An invitation by Welch to pitch in front of GE's most accomplished executives is like winning an Olympic medal in GE's intense locker-room culture." (Wang Guanfu, 2002) In this sentence, what is the "locker-room culture"? In the text, it represents the company's cultural atmosphere of GE. So translators will come to understand what the company culture highly praised by GE is. In American culture, there are usually two explanations of locker-room culture: one is the shady relationship of homosexual lover in one same locker room; the other is the spirit of athletes who share experiences, success and failure before or after contests. After knowing the two implications of locker-room culture and connecting these with the content, it becomes easy to understand the deep meaning the writer wants to convey. That is, in the company culture of GE, staffs have the spirit of athletes, share the experiences and possess the consciousness of competition.

That is the importance of cultural background knowledge. Many texts are written by the writers from English-speaking countries. It is inevitable to have strong local cultural features and habitual expression. This adds the difficulties for translators from non English-speaking countries to understand the texts. Therefore, certain knowledge of the culture and discourse custom of English-speaking countries will greatly contribute to deepening the understanding of Business English translation.

Other background knowledge is business, which is a wide concept. Take the business text about sales achievement of one product as an example, it is necessary to have the concept of product cycle in marketing theory and five stages of product market - introduction stage, growth stage, maturity stage, declining stage and termination stage. Understanding these will greatly improve the rate of the comprehension of the text, for it activates the schema of product cycle.

Translators have certain background knowledge or the building block of schema, but they are not familiar with it. Therefore, they have to read more to activate the schema, and then connect it with the corresponding material. As to the features of Business English translation, translators should read more articles about economy, management, business trade and so on. It can enlarge the knowledge and activate the schema of background knowledge. 


\subsubsection{Activation of professional words and sentences}

Word is the foundation of expressing and constructing the schema, and the important component of language. It contains three kinds of meaning: vocabulary meaning, structural meaning and social \& cultural meaning. Many words are rich in background knowledge. For example, "Greenback" is used to express the US notes because US government issued the notes with green background in order to resolve the financial difficulties caused by the war. So translators can understand and remember them through the knowledge with social and cultural meaning -loaded words.

Most translators cannot understand the texts correctly and quickly mainly because of the limitation of professional words or misunderstanding them, so they have to accumulate professional words through translation. As to the features of words mentioned above, an efficient way is to remember words in translation. Translators can choose several texts of a certain business topic for reading. When translators read some texts about market and marketing, there are some basic words like bear market, futures market, or some words describing price like constant price, contract price. Through this kind of reading, not only can they deepen the understanding of this topic, but also remember the words in the translation process.

What's more, the reflection of Business English texts to economic affairs is very quick and timely. The style is very arbitrary. The writer will use some phrases and slang flexibly to vividly express the meaning, for instance, "black Friday" is usually used to express economic panic. In this situation, translators should connect the content and professional knowledge so as to have a right understanding. The sentences of Business English translation are usually very complicated, and this obvious feature brings about some barrier to translators. Though there are some very long sentences, the structure of them are usually fixed and the language used is very clear. So carefully analyzing the structure is helpful to understanding the meaning.

As for the features of sentences in Business English translation, generally speaking, the basic way of analyzing the long sentences is to find out the main parts of the sentences. Translators ought to learn how to analyze the grammar components of sentences. When analyzing sentences, translators cannot define themselves in one word or one part of components. Through analyzing the whole sentence, they can find out the main components: the subject and predicate and then other auxiliary components (such as attributive components, insert ingredients). The next step is to analyze the relations between parts of sentence. Many sentences are usually in coordinate construction and subordinate construction. In coordinate construction, the clauses are of equal importance. There are semicolons and commas, or the coordinators such as and, but, or, to divide different clauses. In subordinate structure, a subordinate clause is a part of the main clause such as attribute, object, complement, adverbial and so on. They are connected by relative words. The key point of analyzing the long sentences is dividing them into different parts. Firstly, translators should find out the main clause and the parts of the trunk; then analyze the modifiers and judge their logical relationship with the main clause. All in all, the main clause, such as subject, predicate and object, conveys the main information. So finding out the main clause will help translators understand clearly and easily. For example, The sustained and substantial appreciation of the US dollar-more than 31\% since the second quarter of 1995, using the Federal Reserve's broad index of its real (inflation-adjusted) value - greatly stimulated FDI around the world, especially in Mexico, China, and other developing countries. (Wang Guanfu, 2002) Translators may feel very difficult at the first sight of this sentence, for it is too long and complicated. But, when using the way mentioned above, it is easy to understand. Let's find out the main clause. The subject is "the appreciation", and the predicate verb is "stimulated". The object is "FDI". Now the trunk of this sentence is very clear: the appreciation stimulated FDI. The meaning becomes easy to know. Then translators can pay attention to the other auxiliary components. The sentence is not difficult any more. In this way, translators will feel ease to the long sentences. Therefore, the schema of professional words and sentences will be activated.

\subsubsection{Activation of the features of structure}

Towards the features of the structure in Business English translation, translators ought to grasp the whole structure of the texts and the logical thinking ways.

Generally speaking, there are following aspects which help translators keep to the whole structure and logic.

1) Title: it is the high summation of the basic information. It is a short statement and sweeping generalization. It is concise summary. For example, the title of a text is "EU Enlargement". The text must be talking about something related to the enlargement of European Union. So translators can activate some knowledge about the development and enlargement of EU. What's more, sometimes there are subtitles in every part of the whole text. They are the summary of each part.

2) Introduction: generally speaking, it is the first paragraph, summary of the content. Actually, it is also the 
development of the title. Translators can be familiar with what the text is going to say from the title and introduction, so they can find out the main ideas and grasp the main information in the text. Then it is easier to solve the problems concerning details.

3) The topic sentence of one paragraph: although there is introduction summarizing the content of the whole text, translators have to pay attention to the topic sentence. It is a conclusion of one part, and mostly appears in the beginning of one paragraph.

4) The conjunctions in the text: the conjunctions connect two sentences or parts of one sentence. It can help translators understand the logical relation of the content. Translators can correctly analyze and judge the content with the help of conjunctions. In translation, translators pay special attention to disjunctive words, for the part after the disjunctive is always the key point the writer wants to emphasize.

In addition to the above aspects, it is suggested that translators reread the text to deepen the understanding of the main structure and meaning. Therefore, the schema of main structure of Business English translation can be activated. And it can help translators have a general concept of the structure, so translators can know the probable place of the information they need.

\subsection{Construction and extension of schemata}

As the translators can use the background knowledge to compensate for the lack of professional words, obtaining the background knowledge is an important step for constructing the schema. This requires translators to learn more basic knowledge of business, such as economics, management, international commercial law, business culture and so on. Translators can obtain these kinds of background knowledge before translation.

According to the schema theory, Business English translation process is a series of processes made up of predication, choice, testing and confirmation. Translators have to predict and guess the meaning in the translation process. They make use of clues of the texts to predict and choose appropriate schema from different schemata, then use the chosen schema to instruct other variants and make the important one become concrete one. In this process, the schema theory holds that translators make predictions for every part and then choose the most appropriate one from many schemata for mutual communication with the writer. If one item of the information is proved to be wrong, the translators will give it up and choose again. In a sense, translation process is a process of choosing, testing and affirming. So the new schema is to be constructed on the basis of the existing schema.

The extension of schemata includes linguistic extension, content extension and rhetorical extension. Linguistic extension means enlarging the linguistic knowledge like words and grammar. It contributes to the development of understanding. It can be spread out around one or some key words, keeping exact the knowledge chain of professional terms in Business English. For example, when translating texts about ocean marine insurance, there must be some words related to ocean transport and insurance. This kind of texts must contain words like FPA, WPA etc. which translators may not be familiar with. FPA is the abbreviation of Free from Particular Average. Here "Average" means marine loss. FPA means partial loss or non-total loss to a ship or cargo. WPA is short for With Particular Average. They are two kinds of marine loss. After translating this kind of texts, translators will easily understand the terms of this kind and form a knowledge chain of marine insurance. Therefore, translators can construct the information frame of linguistic schemata and then form systematical knowledge about Business English expression.

Content extension refers to the activity after translating. Translators can make use of the existing schema to have different activities, such as retelling, commenting, which will efficiently strengthen the schemata, and expand them. Take "EU Enlargement" for example again, after translating the text, translators can have general knowledge about the development of EU. Through retranslating or retelling, translators can clearly remember which countries are the member countries of EU, which are going to be its members, and its accession of process, etc. This can help translators find out some ignored information, then strengthen and enlarge the schemata.

Rhetorical extension is the extension of the structure knowledge of the text. That is the recapitulative grasp of the top structure, which is very helpful to remembering the information chain. These three kinds of extension form the extension of schemata. Through this kind of extension, translators can have a better understanding as a result of improving themselves in translating Business English text. Actually the extension of schemata is equal to the construction of schemata. They aim at enlarging the concept of the background knowledge, professional words and sentences as well as structure. In this way, the schema existing in the mind will become a gradually increasing systematic structure.

\subsection{Improvement of Business English translation ability through schema}

To comprehend the Business English texts, the translators have to resort to a series of psychological activities. They 
will make use of the schema consciously or subconsciously on the information, activate the background knowledge, predict the subsequent information, comprehend the input knowledge, deduce the implicit concept or intention and induce the general meaning of the text. Therefore, the role of the schema theory in Business English translation will help translators acquire the translation skill and improve their Business English translation ability.

In the above part, the schema is to be activated and constructed in some way. After the activation of existing schemata and the construction of new schemata, the functions of schemata in Business English translation will take effect. When they come across a word like "offer", they will know its meaning in Business English context, not the meaning in General English. And the background knowledge appears in the mind: that is, an offer is made when a seller promises to sell goods at a stated price within a stated period of time. And therefore, translators will not misunderstand the material, and they can feel easy in the translation process. The problem of the syntactic deficiencies will be solved. As to the background knowledge, it is enlarged in the process of abundant translation. More knowledge relative with business translators obtain, more choices they have in applying schema to translation.

Through schema, translators solve the problems of the background knowledge and syntactic deficiencies, making the translation process go quite smoothly. Meanwhile, translators can read a text quickly, efficiently, and find the information in the right place timely, grasp the right meaning of the content, understand the whole text completely. Thus their Business English translation ability can be strengthened and improved.

\section{Conclusion}

According to the above analysis, translation is a complicated process. Translators cannot understand the Business English text totally and completely, only dealing with the text itself, for, beyond the text, there are many factors affecting the translation process. Therefore, translators have to know some more knowledge beyond the text like relative business courses and the systematic knowledge. This requires translators to read more widely to strengthen their schemata. In this way, the existing schemata can be activated, and accordingly the new schemata can be constructed and extended. Then they are able to deepen the understanding of Business English texts gradually, and apply the schemata smoothly in the translation process, thereby, fundamentally enhancing the Business English translation ability.

\section{References}

David W. Carroll. (2000). Psychology of Language. Beijing: Foreign Language Teaching and Research Press, pp. $112-116$

Gui Shichun. (2000). Newly Edited Psychological Linguistics. Shanghai: Shanghai Foreign Language Education Press, pp. 117-120

Kant. (2003). Critique of Pure Reason. Beijing: Commercial Press. pp. 105-107

Lin Ting. (1996). Applying Schema Theory and Improving Reading Effect. Modern Foreign Language. No.4, 29-30. via CNKI Grid-20 database platform. [Online] Available: http://www.cnki.com.cn/Article/CJFD1996-XDWY604.006.htm

Wang Guanfu. (2002). English Readings in International Business. Beijing: Higher Education Press, pp. 99-214

Wang Junjie, Wu Fang. (2008). An Exploration into the Language Characteristics of Business English. Exam Weekly, $12,88-90$

Wedell M., Liu Runqing. (1995). Language Teaching \& Learning from Theory to Practice. Beijing: Higher Education Press. pp. 87-90

Wu Feng. (2005). Ways and Approaches to Improving Business English Reading Ability. Journal of Jilin Overseas Chinese University of Foreign Languages, 1, 30-36

Yang Chaoguang. (2007). An Introduction to Linguistics. Beijing: University of International Business and Economics Press. pp. 45-46

Yuan Bo. (1997). The Relationship Between Schema Knowledge and Reading Comprehension Mode. Foreign Language Research, 4, 51-58

Zhang Biyin. (1995). Reading psychology. Beijing: Beijing Normal University Press. pp. 72-73

Zhao Yanfang. (2000). Overview of Cognitive Linguistics. Shanghai: Shanghai Foreign Language Education Press. pp. $48-50$

Zuo Li. (2007). Schema Theory and College English Reading Teaching. Journal of Wuhan Vocational and Technical College of Engineering, 4, 11-18 